\title{
Study of heart disease in pregnancy and its effect on maternal outcome
}

Nitin Kumar Jain, Shabana Sultan*

Department of Obstetrics and Gynecology, Gandhi Medical College, Bhopal, Madhya Pradesh, India

Received: 09 June 2019

Accepted: 24 June 2019

\section{*Correspondence:}

Dr. Shabana Sultan,

E-mail: drshabanasultan@gmail.com

Copyright: ( $)$ the author(s), publisher and licensee Medip Academy. This is an open-access article distributed under the terms of the Creative Commons Attribution Non-Commercial License, which permits unrestricted non-commercial use, distribution, and reproduction in any medium, provided the original work is properly cited.

\section{ABSTRACT}

Background: Heart diseases in pregnant women and has higher incidence of maternal mortality and morbidity and is regarded as risk factor for unfavourable outcome of pregnancy both for the mother and the foetus. Heart disease in pregnancy was found to be second indirect cause contributing to maternal mortality in India.

Methods: This study is a hospital based prospective analytical study carried out in the Department of Obstetrics and Gynaecology, Sultania Zanana Hospital, Gandhi Medical College, Bhopal over a period of 1 year from $1^{\text {st }}$ March 2017 to $28^{\text {th }}$ February 2018. Patients were evaluated clinically by both obstetrician and cardiologist and followed all through their hospital stay till discharge.

Results: Total 51 cases of heart disease were found during the study period. Incidence of heart disease in our study during study period was found $0.25 \%$. Most patients were unbooked 33(64.71\%) and maximum number of patients belonged to NYHA functional class II 24 (47.06\%), RHD cases were 4 times more common than CHD. 24 (47.06\%) patients had undergone surgical intervention for heart disease. Congestive cardiac failure was most common complication seen. Three maternal deaths were seen. All cases belonged to NYHA functional class III. All 3 cases were unbooked presented first time in labor.

Conclusions: We found that pregnancy outcome was good in booked cases with regular checkup by obstetrician and cardiologist, surgically corrected cases and those with NYHA functional class I and II. Hence, joint management by obstetrician, cardiologist, and anesthetist is required to ensure better maternal outcome.

Keywords: Congenital heart disease, Heart disease, Maternal outcome, Maternal mortality, Pregnancy, Rheumatic heart disease

\section{INTRODUCTION}

Heart diseases in pregnant women and has higher incidence of maternal mortality and morbidity and is regarded as risk factor for unfavourable outcome of pregnancy both for the mother and the foetus.

Prevalence of heart disease in pregnancy varies from 0.3$3.5 \% .^{1,2}$ Incidence of cardiac disease complicating 1 to $4 \%$ of pregnancies in India. ${ }^{3}$ In developing countries like India, Rheumatic heart disease is still predominate and comprises $89 \%$ of cases. ${ }^{4}$ Which is because poor sanitary condition, resulting in repeated childhood streptococcal infection in rural areas. In India, the rheumatic heart disease contributes to approximately $69 \%$ of cardiac disorders seen in pregnancy. ${ }^{5}$

The maternal mortality rate in women with cardiac disease is as high as $7 \%$, and morbidity rate higher than $30 \%$ during pregnancy. ${ }^{6}$ Heart disease in pregnancy was found to be second indirect cause contributing to maternal mortality in India. ${ }^{7}$ Maternal functional status is a most important predictor of outcome and most often defined by NYHA functional class. ${ }^{8}$ Poor functional 
status and cyanosis are mostly associated with adverse maternal and neonatal outcome. ${ }^{9}$

There are few studies available in India that are prospective, focused particularly on heart disease in pregnancy, and examined the populations managed at different institutions in different parts of country. ${ }^{5}$ Pregnancy related complications that compound the heart disease is ignored in the rural setup and patients rarely seek proper early care. ${ }^{10}$

With pregnancy-induced anatomical and functional changes in cardiac physiology can have a profound effect on underlying heart disease. In the presence of maternal heart disease, the cardiovascular changes of pregnancy may result in decompensation and even demise of the mother or fetus. ${ }^{2,8,11}$ Cardiovascular decompensation during labor may manifest as pulmonary edema with hypoxia or as hypotension, or both.

This prospective study has been conducted in department of obstetrics and gynaecology, Sultania Zanana Hospital, Gandhi Medical College Bhopal to evaluate effect of heart disease on pregnancy and feto-maternal outcome. The results can also be useful to increase awareness in patients regarding heart disease and other medical disorders during routine antenatal care.

\section{METHODS}

This study is a hospital based prospective analytical study carried out in the Department of Obstetrics and Gynaecology, Sultania Zanana Hospital, Gandhi Medical College, Bhopal over a period of 1 year from $1^{\text {st }}$ March 2017 to $28^{\text {th }}$ February 2018. Patients who meet the inclusion criteria at the time of admission and during their hospitalization were included in the study after taking proper consent.

\section{Inclusion criteria}

- All obstetric patients admitted with heart disease and diagnosed after admission in study centre during study period were included in this study.

\section{Exclusion criteria}

- Patients other than heart disease.

All obstetric patients with heart disease admitted at study centre. Data was collected from consenting females with written consent in their own language with the help of performed tests and clinical questionnaire which contain demographic characteristics, educational status, parity, gestational age, prior cardiac events, prior surgery/intervention, medication, cardiac lesions, New York Heart Association (NYHA) functional class, comorbid conditions, clinical characteristics by interview technique and their proforma was filled, then we followed the patient and maternal outcome was coded appropriately and data collected was compiled using MS EXCEL and is presented in the form of percentage and proportion. Classification of severity of heart disease was done using NYHA functional classification.

All relevant investigations were done including ECG and echocardiography and they were evaluated clinically by both obstetrician and cardiologist. Management was planned by cardiologist and obstetrician according to the condition of patient, NYHA functional status, and type of cardiac lesion, cardiovascular stability, and duration of pregnancy and viability of foetus. Patients were managed as per advice of cardiologist and obstetrician as joint approach.

After delivery patient was assessed for wellbeing and cardiac and obstetric complications. Maternal morbidity was assessed by observing maternal complications such as pulmonary edema and/or cardiac arrhythmia acute respiratory distress atrial flutter/fibrillation Embolic strokes pulmonary hypertension heart failure, transient ischemic attack, and maternal death.

Foetal outcome was assessed by the maturity, babies referred to NICU, still births and perinatal mortality and congenital cardiac anomaly. Patient was followed all through their hospital stay till discharge.

\section{Statistical analysis}

Collected data were entered into Microsoft excel spreadsheet and were analyzed. Comparison of the maternal outcome amongst NYHA functional class, and according to booking status and prior surgical intervention for heart disease was made by applying chi square test. $\mathrm{P}$ value $<0.05$ was considered as significant.

\section{RESULTS}

Total number of obstetric admissions in our Hospital during study period was 20328. Total 51 cases of heart disease were found during the study period. Incidence of heart disease in our study during study period was found $0.25 \%$.

Majority of patients of heart disease present were in age group 20-30 years. As early marriages are still common most women with pregnancy were seen in this age group. Majority of patients were educated till middle school 14 $(27.45 \%)$ and $14(27.45 \%)$ less then middle school (Literate). Only $3(5.88 \%)$ patients were illiterate.

Maximum of patients were from low socio economic class. Upper lower class $36(70.59 \%)$ and lower middle $12(23.53 \%)$. In this study urban patients were 30 (58.82\%) and rural patients were 21 (41.18\%). As our Sultania Zanana Hospital is located in centre of the city we cater both rural and urban population. Primigravida were $22(43.14 \%)$ and $2^{\text {nd }}-4^{\text {th }}$ gravida were $31(60.78 \%)$ and $5^{\text {th }}$ gravida was $1(01.96 \%)$ (Table 1$)$. 
Table 1: Demographic parameters.

\begin{tabular}{|lll|}
\hline Age group & Total number & Percentage \\
\hline$\leq 20$ years & 1 & $(1.96 \%)$ \\
\hline $21-30$ years & 26 & $(50.98 \%)$ \\
\hline 26-30 years & 21 & $(41.18 \%)$ \\
\hline$>30$ years & 3 & $(5.88 \%)$ \\
\hline Educational status & 3 & $(05.88 \%)$ \\
\hline Illiterate & 14 & $(27.45 \%)$ \\
\hline $\begin{array}{l}\text { Literate, less then } \\
\text { middle school }\end{array}$ & 28 & $(54.90 \%)$ \\
\hline $\begin{array}{l}\text { Middle to higher } \\
\text { secondary school }\end{array}$ & 6 & $(11.76 \%)$ \\
\hline \begin{tabular}{l} 
Graduate \\
\hline Socioeconomic status
\end{tabular} & 03 & $(05.88 \%)$ \\
\hline II Upper middle class & 03 & $(23.53 \%)$ \\
\hline III Lower middle class & 12 & $(70.59 \%)$ \\
\hline IV Upper lower class & 36 & \\
\hline Residence & & $(41.18 \%)$ \\
\hline Rural & 21 & $(58.82 \%)$ \\
\hline Urban & 30 & $(43.14 \%)$ \\
\hline Parity & 22 & $(60.78 \%)$ \\
\hline Primigravida & 31 & $(01.96 \%)$ \\
\hline $2^{\text {nd }}-4^{\text {th }}$ gravida & \\
\hline $5^{\text {th }}$ gravida and above & 01 & \\
\hline & & \\
\hline
\end{tabular}

Most patients were unbooked $33(64.71 \%)$ and 18 $(35.29 \%)$ were booked. This clearly indicates towards lower awareness and non-compliance with medical treatment is even with existing heart disease. Majority of patients did not have regular antenatal checkups and cardiology OPD visits (Figure 1).

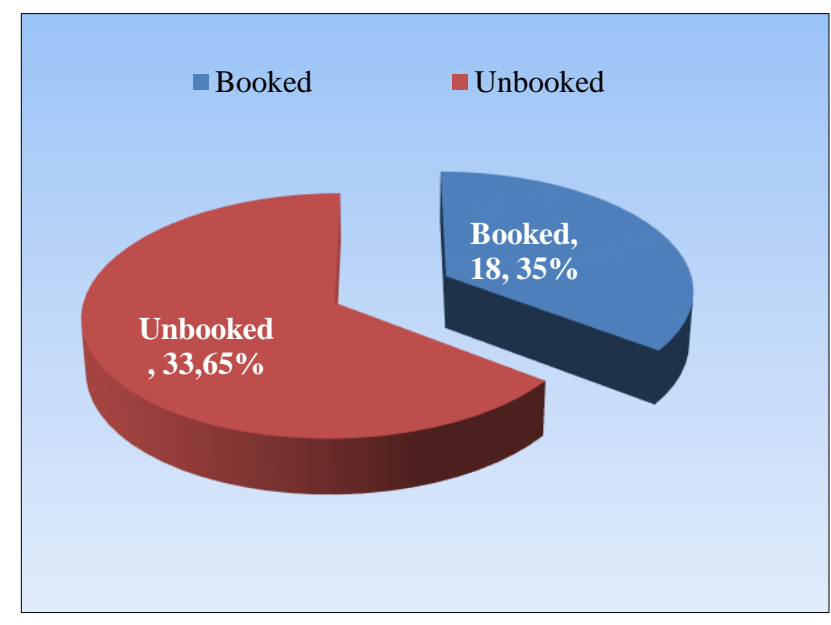

Figure 1: Distribution of patients of heart disease according to booking status.

Maximum number of patients belonged to NYHA functional class II $24(47.06 \%), 14(27.45 \%)$ from class I, $11(21.57 \%)$ from class III and only $2(3.92 \%)$ from class IV. Most of the patients were in NYHA class I and II but around one fourth of total patients belonged to NYHA class III and IV (Figure 2).

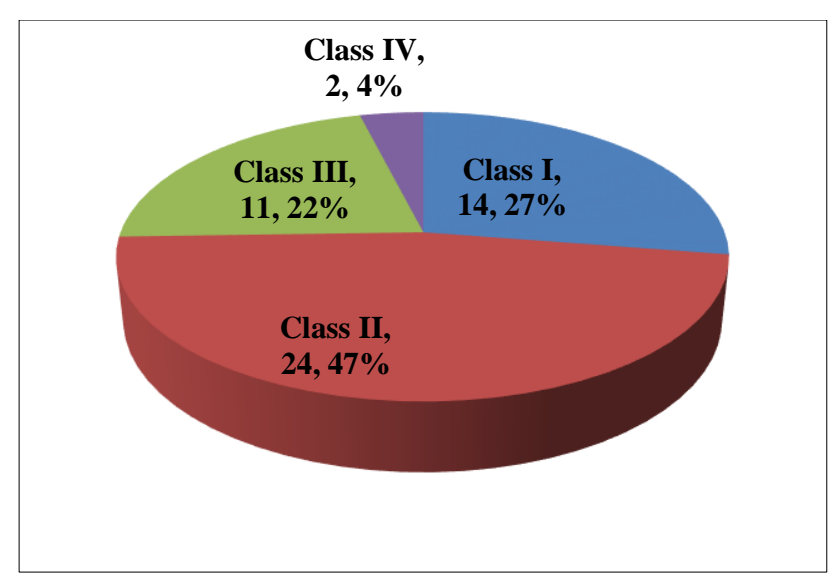

Figure 2: Distribution according to NYHA functional class.

Table 2: Distribution of heart disease according to surgical intervention.

\begin{tabular}{|llll|}
\hline $\begin{array}{l}\text { Type of heart } \\
\text { disease }\end{array}$ & Total & $\begin{array}{l}\text { Surgically } \\
\text { corrected }\end{array}$ & $\begin{array}{l}\text { Not } \\
\text { corrected }\end{array}$ \\
\hline Congenital & 9 & 8 & 1 \\
\hline Rheumatic & 42 & 16 & 26 \\
\hline Total & $\mathbf{5 1}$ & $\mathbf{2 4}(\mathbf{4 7 . 0 6 \% )}$ & $\mathbf{2 7 ( 5 2 . 9 4 \% )}$ \\
\hline
\end{tabular}

RHD cases were 4 times more common than CHD. This table shows that $24(47.06 \%)$ patients had undergone surgical intervention for heart disease rest 27 (52.94\%) were uncorrected. Among CHD patients 8 (88.89\%) out of 9 were surgically corrected and $16(38.1 \%)$ out of 42 of RHD patients were surgically corrected. Three cases were corrected VSD 3 cases were corrected VSD and 1 each of corrected PDA and 1 case of TGA (Table 2).

Among obstetrics co-morbidities hypertensive disorders of pregnancy (gestational hypertension 3, preeclampsia 2) $5,9.80 \%$ were most commonly seen. Oligohydramnios was seen in $3(5.88 \%)$ cases. Anemia $5(9.80 \%)$ and hypothyroidism $3(5.88 \%)$ were most common medical co-morbidities seen.

Table 3: Distribution of patients of heart disease according to mode of delivery.

\begin{tabular}{|llll|}
\hline \multirow{2}{*}{ Mode } & & $\begin{array}{l}\text { Number of } \\
\text { patients }\end{array}$ & Percentage \\
\hline \multirow{2}{*}{ Vaginal } & Spontaneous & 28 & $54.9 \%$ \\
\cline { 2 - 4 } & Induced & 5 & $9.8 \%$ \\
\hline Caesarean section & 18 & $35.3 \%$ \\
\hline Total & $\mathbf{5 1}$ & $\mathbf{1 0 0 \%}$ \\
\hline
\end{tabular}

Total vaginal deliveries were $33(64.7 \%), 28(54.9 \%)$ were spontaneous and in $5(9.8 \%)$ patients labour was induced due to hypertensive disorder of pregnancy and postdatism. Caesarean sections were done in 18 (35.3\%) patients (Table 3). 
Congestive cardiac failure was most common complication seen in four $(7.84 \%)$ patients, atrial fibrillation in three $(5.88 \%)$ and pulmonary arterial hypertension were seen in three $(5.88 \%)$ patients.

Three maternal deaths were seen. Causative lesions seen were moderate to severe MR, Mild TR and severe TR. Cause of deaths seen were congestive cardiac failure, atrial fibrillation and pulmonary Artery Hypertension respectively. All cases belonged to NYHA functional class III. All 3 cases were unbooked presented first time in labor. Associated complication was severe preeclampsia.

\section{DISCUSSION}

In our study incidence of heart disease was $0.25 \%$. This was comparable with studies by Pujitha KS Et Al $(0.21 \%)$ and Indira $\mathrm{I}$ et al $(0.43 \%){ }^{12,13}$ But higher incidence were seen in studies by Nagamani $G$ et al (1.2\%), Priya HL et al (1.72\%), Gayathri HA et al $(1.82 \%)$ and Selvarani $G$ et al $(4.7 \%) .{ }^{14-17}$ This is probably due to our centre being tertiary care centre where most of the patients are referred from other centers.

In present study majority of patients $26(50.98 \%)$ were in age group 20-30 years, similar results were obtained in other studies by Konar $\mathrm{H}$ et al $(43.4 \%)$, Priya HL et al $(54.4 \%)$, Nqayana T et al $(37.89 \%)$ and Gayathri HA et al $(84 \%)^{5,15,16,18}$ This indicate that in our country early marriage, illiteracy and lack of contraception are quite prevalent mainly responsible for early pregnancy.

In our study maximum of patients were primigravida 22 $(43.14 \%) 2^{\text {nd }}$ gravida were $12(23.53 \%) 3^{\text {rd }}$ gravid were $13(25.49 \%) 4^{\text {th }}$ gravida were $3(5.88 \%)$ and $5^{\text {th }}$ gravida was $1(01.96 \%)$. Similar results were obtained in studies by Konar H et al (G1 44.13\%, G2 35.94\%), Selvarani G et al (G1 55.7\%, G2 40.5\%), Indira I et al (G1 42\%, G2 $32 \%)$, and Gayathri HA et al (G1 51\%, G2 $29 \%)^{5,15,16,18}$

This shows that most patients were primi or second gravida but multigravidity is not uncommon. This indicates lack of awareness as well as understanding of complications and risk associated with heart disease in pregnancy.

In our study most patients were unbooked $33(64.71 \%)$ and $18(35.29 \%)$ were booked similar results were seen in study by Indira I et al (Booked $40 \%$, Unbooked 60\%) and Nagamani G. et al (Booked 48\%, Unbooked 52\%). ${ }^{13,14}$ In study by Gayathri HA et al (Booked 56\%, Unbooked $44 \%$ ) higher percentage of booked patients was seen but unbooked patients were also seen in significant numbers. ${ }^{16}$

This shows less adequate coverage of antenatal care as well as diagnosis of heart disease later in pregnancy or after development of complications. This contributes to increased morbidity and mortality in patients of heart disease.

Maximum number of patients in our study belonged to NYHA functional class II $24(47.06 \%), 14(27.45 \%)$ from class I, $11(21.57 \%)$ from class III and only $2(3.92 \%)$ from class IV. Similar results were seen in other studies by Konar $\mathrm{H}$ et al (class I and II $83.27 \%$, class III $15.30 \%$ and class IV $0.14 \%$ ), Joshi G et al (class I and II $61.9 \%$, class III $23.8 \%$ and class IV $14.3 \%$ ), Siu SC et al (class I and II $96 \%$, class III $4 \%$ and class IV $4 \%$ ) and Nqayana $\mathrm{T}$ et al (class I $40 \%$, class II $34.74 \%$ class III $16.84 \%$, class IV $8.42 \%)$. $^{4,5,18,19}$

In our study among CHD patients $8(88.89 \%)$ out of 9 were surgically corrected and $16(38.1 \%)$ out of 42 of RHD patients were surgically corrected. In study by Nqayana $\mathrm{T}$ et al (Corrected RHD 33.77\%, Corrected CHD $88.89 \%$ ), similar result were seen but in studies by Indira I et al (Corrected RHD 15\%, Corrected CHD 9\%) and Konar H et al (Corrected RHD 10.26\%), incidence of surgical correction was found comparatively low. $5,13,18$ This shows that with increased access and development in surgical technique people are that more people are being treated surgically and outcomes are better now.

Among obstetrics co-morbidities hypertensive disorders of pregnancy (Gestational hypertension 3, preeclampsia 2) $5(9.80 \%)$ were most commonly seen. Oligohydramnios was seen in $3(5.88 \%)$ cases. Anemia 5 $(9.80 \%)$ and hypothyroidism $3(5.88 \%)$ were most common medical co-morbidities seen.

In studies by Konar $\mathrm{H}$ et al (Preeclmpsia 1.42\%) and Priya $\mathrm{HL}$ et al (Gestational hypertension $2.7 \%$, preeclampsia $2.7 \%$, moderate anemia $4.1 \%$, hypothyroidism $2.7 \%$ ) comparatively low proportion of hypertensive disorders were seen while in study by Nqayana $\mathrm{T}$ et al (Anemia 13.68\%) comparatively higher incidence of anaemia was seen. ${ }^{5,15,18}$

This indicates that even with existing heart disease and other co-morbidities women still opts for a pregnancy without prior correction which in turn contributes to increased morbidity and mortality. This shows lack of awareness and casual attitude towards pregnancy associated heart disease and its serious effect on maternal and fetal outcome.

In our study vaginal deliveries were $64.7 \%$ and caesarean sections were $35.3 \%$ while in studies by Siu SC et al (VD $73 \%$, LSCS 27\%), Konar $\mathrm{H}$ et al (SVD 46.6\%, Induced $3.2 \%$ LSCS $33 \%$ ) and Priya HL et al (VD $70 \%$, LSCS $30 \%$ ) similar results were seen. But in study by Indira I et al (VD 53.33\%, LSCS 3.33\% Forceps 26.66\%) comparatively low proportion of caesarean section were seen probably due to increased rate of forceps deliveries. ${ }^{4,5,13,15}$ 
In our study congestive cardiac failure was most common complication seen in $4(7.84 \%)$ patients atrial fibrillation and pulmonary arterial hypertension were seen in $3-3$ $(5.88 \%)$ patients.

Our study results are similar to study done by Konar $\mathrm{H}$ et al (CCF $7.4 \%$, AF $5.33 \%$ ) but low proportion of complications were seen in study by Indira I et al (CCF $3.33 \%$, Acute pulmonary edema $3.33 \%)$. $^{5,13}$ This is probably due to higher proportion of unbooked patients in our study. In studies by Pujitha KS et al (CCF 9\%, AF $9 \%, \mathrm{PAH} 4.5 \%$ ) and Nqayana $\mathrm{T}$ et al (CCF 9.74\%, AF $23.64 \%$ ) higher rates of complications were seen. ${ }^{12,18}$ In this study 3 maternal cardiac deaths were seen. Causative lesions seen were moderate to severe MR, Mild TR and Severe TR.

Cause of deaths seen were congestive cardiac failure, atrial fibrillation and pulmonary artery hypertension respectively. All cases belonged to NYHA functional class III. All 3 cases were unbooked presented first time in labor.

Similaraly in studies by Konar $\mathrm{H}$ et al $(3,1.1 \%$ all Unbooked cases seem first time in labor, complications were CCF and Pulmonary edema) and Indira I et al (4, $6.6 \%$ two due to acute pulmonary edema and 2 due to CCF, all 4 were Unbooked cases) all maternal deaths were seen in NYHA class $\geq$ III and were in unbooked patients. ${ }^{5,13}$ Similarly, in studies by Konar $\mathrm{H}$ et al, Indira I et al, Joshi G et al and Pujitha KS et al cause of deaths were cardiac complications as CCF, Pulmonary edema and cardiac arrest. ${ }^{5,12,13,19}$

\section{CONCLUSION}

This study has demonstrated a need for joint interdisciplinary approach in cases of pregnancy complicated with heart disease and also higher risk of maternal morbidity and mortality in unbooked and previously untreated for heart disease patients.

Higher number of heart disease patients detected for first time in labor indicates low percentage of antenatal checkups as well as substandard antennal care. Routine cardiovascular examination at first and subsequent antenatal visits is necessary for early detection and management thus reducing maternal and neonatal morbidity and mortality.

Funding: No funding sources

Conflict of interest: None declared

Ethical approval: The study was approved by the Institutional Ethics Committee

\section{REFERENCES}

1. Surge D, Blake S, McDonald D. Pregnancy complicated by maternal heart disease at the National Maternity Hospital, Dublin. 1969-1978.
2. McFaul P, Dornan J, Lamki H. Pregnancy complicated by maternal heart disease. A review of 519 women. Br J Obstet Gynaecol. 1998;95:861-7.

3. Bansode BR. Pregnancy and heart disease. Assoc Physicians Ind. 2010;773-6.

4. Siu SC, Sermer M, Colman JM. Prospective multicenter study of pregnancy outcome in women with heart disease. Circulation. 2001;104:515-21.

5. Konar H, Chaudhuri S. Pregnancy complicated by maternal heart disease: a review of 281 women. J Obstet Gynaecol India. 2012;62(3):301-6.

6. Pushpalatha K. Cardiac diseases in pregnancy- A review. JIMSA. 2010;23(4):269-74.

7. Kulkarni S, Huligol A. Maternal mortality -10 years study. J Obstet Gynecol Ind. 2001;51(2):155-8.

8. Whittemore R, Hobbins JC, Engle MA Pregnancy and its outcome in women with and without surgical treatment of congenital heart disease. Am J Cardiol. 1982;50(3):641-51.

9. Siu SC, Sermer M, Harrison DA, Grigoriadis E, Liu $\mathrm{G}$, Sorensen $\mathrm{S}$, et al. Risk and predictors for pregnancy-related complications in women with heart disease. Circulation. 1997;96(9):2789-94.

10. Sawhney H, Aggarwal N, Suri V, Vasishta K, Sharma Y, Grover A. Maternal and perinatal outcome in rheumatic heart disease. Int J Gynaecol Obstet. 2003;9-14.

11. Shime J, Mocarski E, Hastings D. Congenital heart disease in pregnancy: short- and long-term implications. Am J Obstet Gynecol. 1987;156:31322.

12. Pujitha KS, Sheela SR, Jyothi NS. A study of maternal and fetal outcome in cardiac disease in pregnancy at tertiary care center. Int J Reprod Contracept Obstet Gynecol. 2017;6:5095-8.

13. Indira I, Jyothi SK. Study of pregnancy outcome in maternal heart disease. IOSR J Dental Med Sci (IOSR-JDMS). 2015;14(7):e-ISSN:2279-0853.

14. Nagamani G, Bhavani K, Vani Isukapalli, Lagudu S. Heart disease in pregnancy prospective study from southern India. Int J Current Med and Applied Sci. 2015;6(1):8-12.

15. Priya HL, Bhandiwad A, Desai N, Kondareddy T. Maternal outcomes of rheumatic heart disease in pregnancy. Int J Reprod Contracept Obstet Gynecol. 2017;6:802-6.

16. Arunachalam HG, Kodey PD, Gangadhara, Rao K, Satish RJ, Mounica E. Prospective study on heart disease complicating pregnancy. Int $\mathbf{J}$ Current Microbiol Applied Sci. 2015;4(8):215-22.

17. Selvarani G, Sivakumar GS, Swaminathan N, Ravishankar G, Paul GJ, Ramesh R, et al. Prevalence study on heart diseases among antenatal mothers. Int J Sci Stud. 2017;5(5):204-8.

18. Nqayana T, Moodley J, Naidoo DP. Cardiac disease in pregnancy. Cardiovas J Africa. 2008;19(3):14551.

19. Joshi G, Joshi SC, Jha SK, Singh Y, Joshi A. Maternal heart disease and pregnancy outcome: Findings from a retrospective cohort in a tertiary care 
government hospital in Haldwani, Nainital. Nig J Cardiol. 2015;12:120-3.
Cite this article as: Jain NK, Sultan S. Study of heart disease in pregnancy and its effect on maternal outcome. Int J Reprod Contracept Obstet Gynecol 2019;8:3031-6. 